\title{
Chronic Illnesses and Student Academic Performance
}

\author{
Therdpong Thongseiratch, M.D. ${ }^{1}$, Nutthaporn Chandeying, M.D. ${ }^{2}$
}

\author{
'Department of Pediatrics, Faculty of Medicine, Prince of Songkla University, Hat Yai, Songkha 90110, Thailand. \\ 2Department of Obstetrics and Gynecology, Faculty of Medicine Vajira Hospital, Navamindradhiraj University, \\ Dusit, Bangkok 10300, Thailand. \\ Received 20 November $2019 \bullet$ Revised 22 February 2020 • Accepted 10 March $2020 \bullet$ Published online 1 May 2020
}

\begin{abstract}
:
Innovations in healthcare have improved survival in children with illnesses previously considered fatal. Chronic illnesses in school-age children are increasing significantly, and these children are at higher risk for school problems than their healthy peers. To review the state of research on the impact of chronic illnesses on student academic performance, we reviewed original studies that investigated the relationship of child development, cognitive abilities, and academic achievement with common chronic illnesses. Research reveals evidence that chronic illnesses have both direct (educational impacts) and indirect (social and psychological impacts) impacts on education. Specifically, epilepsy, asthma, diabetes mellitus, cancer, congenital heart diseases, and Human Immunodeficiency Virus infection affect student achievement and some specific areas of cognitive ability. Success at school for the chronically ill student requires the coordinated efforts of educators, parents, students, and medical professionals. This review also proposes ways to assess and assist children with chronic illnesses in different educational settings. Hospital schooling, homebound instruction, and school-based interventions are examined. The critical aspects of each educational service are discussed with recommendations for educators and healthcare practitioners.
\end{abstract}

Keywords: academic performance, chronic illness, identification, intervention

Contact: Asst. Prof. Therdpong Thongseiratch, M.D.

Department of Pediatrics, Faculty of Medicine, Prince of Songkla University, Hat Yai, Songkha 90110, Thailand.

E-mail: therd@gmail.com
J Health Sci Med Res 2020;38(3):245-253 doi: $10.31584 /$ jhsmr.2020738 www.jhsmr.org 


\section{Introduction}

A number of childhood diseases that were previously fatal can now be successfully treated and cared as chronic illnesses. ${ }^{1}$ Chronic illnesses are defined as physical conditions that affect an individual's ability to function for intervals longer than three months, or for a duration of hospitalization longer than one month. ${ }^{2}$ Chronic illnesses include: asthma, cancer, diabetes, chronic renal impairment, epilepsy, congenital heart anomaly, obesity, and hematologic diseases. While survival have improved, a critical consideration of their impact upon school performance is required.

Approximately $15.0 \%$ of school-age children in the United States ${ }^{3}$ and Europe ${ }^{4}$ suffer from chronic illnesses, and $50.0 \%$ of these children experience some degree of school performance problems. ${ }^{5}$ A common pitfall in the management of these students is the assumption that the treatment outcomes of chronic illnesses are solely medical. Although educational problems in children with chronic illnesses may not be severe enough to catch the attention of teachers and parents, these children are usually falling behind when compared to their healthy peers and also children with other educational disabilities. ${ }^{5}$ This review considers both the current views regarding the impact of chronic illness and the recommended management strategies aimed at enhancing a child's school performance.

\section{Common impacts across illnesses}

The impacts of chronic illnesses can be divided into three major categories: social impacts, psychological impacts, and educational impacts; all of which influence a child's school performance in both direct and indirect ways.

\section{Social impact}

Children with chronic illness are at higher risk for developing social impairments compared to their peers because of limitations associated with their chronic illness. They have fewer social opportunities to communicate with their healthy peers, restricted play physical activity capabilities, or feelings of alienation from peers. ${ }^{6}$ They are also at an increased risk of being bullied by peers because of their special care needs. ${ }^{7}$ Both children and their parents have reported deficits in social competence. ${ }^{6}$ Social skill interventions are necessary for some children with chronic illnesses who have severe problems. An assessment of social competence, including parent and child perspectives, should be provided to guide intervention decisions. ${ }^{7}$ The inclusion of children with chronic illnesses into a traditional school setting with consistent school attendance provides them with opportunities for developing peer relationships and contributions to a child's social competence.,

\section{Psychological impact}

Approximately one-fifth of children with chronic illnesses have emotional or behavioral problems ${ }^{10}$ that are also likely to impact child's academic performance. ${ }^{11}$ Although these problems are normal responses to their illnesses, early intervention and even prevention are needed when they impair a child's ability to function. Sign of anxiety or depression (e.g., loss of interest, poor appetite, and insomnia) are common in chronically ill children and usually overlooked or undertreated. Depressive symptoms can be found to be as high as $68.0 \%$ in children with severe chronic illness. ${ }^{10}$ Children with chronic illness with a history of repeated hospitalizations usually experience anxiety. ${ }^{12}$ Research found that many factors can contribute to the developing of anxiety symptoms in chronically ill children such as genetic predisposition, illness-related pathogenesis. Psychotropic medications should be prescribed for children with depression and anxiety disorders in order to improve their overall functioning, including better school performance outcomes. ${ }^{10,11}$ 


\section{Educational impacts}

Chronic illnesses early in a child's life adversely affect school performance in many aspects regardless of ethnicity, socioeconomic status, or grade level. ${ }^{13,14}$ Approximately half of children with chronic illness are absent from school for a significant amount of time comparing to their healthy peers. Absenteeism are commonly lead to the requirement of instructional adaptations, such as developing of individual education programs, placement in special education, or grade repetitions. ${ }^{15}$ They are absent from school for an average of 16 days a year compared to 3 days for healthy peers. ${ }^{6}$ Moreover, some chronic illnesses cause a more serious problems on school attendance. For example, childhood leukemia or other cancers absence approximately 40 days during the induction phase of treatment and have inconsistent attendance in the maintenance phase. ${ }^{6}$ However, the specific disease is not always the best predictor for absenteeism. Rather, the chronicity of the illness, parental responses to the illness, parental educational level, and ability of the child to participate in physical activities are better indicators. ${ }^{16}$

Besides poor school performance related to school absenteeism, illness severities and adverse effects of treatment regimens also contribute to cognitive impairment in children with chronic illnesses. ${ }^{17}$ For example, Childhood leukemia survivors face significant learning difficulties due to previous brain radiation and aggressive chemotherapy in treatment protocols which has an impact on memory, attention, and processing speed. ${ }^{6}$

Moreover, children with chronic illnesses may lack of leaning motivation for a number of reasons. Illness symptoms or the adverse effects of treatment regimens can cause fatigue, drowsiness, and irritability, which reduces their motivation to study. ${ }^{6}$ This places a significantly increased burden on teachers to accommodate these children as they attempt to maximize their academic performance.

\section{Disease-specific impacts Epilepsy}

Poor academic performance has been reported among children with epilepsy. ${ }^{18,19}$ Twenty to 30 percent of children with epilepsy have intellectual disabilities [intelligence quotient $(\mathrm{IQ})<70$ ] which lead to very poor learning outcome. ${ }^{20-22}$ However, poor academic performance have been present even in some children with epilepsy who function at the average IQ. ${ }^{18}$ Previous studies showed other potential contributory factors to educational difficulties include specific cognitive deficits or behavioral problems ${ }^{23,24}$ Epilepsy related to the impairment of mental processing, fine motor skills, and visual motor speed. ${ }^{25}$ Not only visible seizures may interrupt learning, but also epileptiform discharges occurring in the brain between seizures may also disrupt learning processes and influence academic performance. Suppression of discharges is associated with a significant improvement in school function. ${ }^{26,27}$

\section{Diabetes mellitus}

Diabetes mellitus (DM) is a metabolic disease that can cause complications in several organs, including the kidney, eyes, and brain. ${ }^{27}$ Children with type 1 and 2 DM may present with cognitive dysfunctions. Previous studies have demonstrated an association between early onset diabetes, poorly-controlled diabetes, and frequent hypoglycemia and poor cognitive ability. ${ }^{27}$ Both hyperand hypo- glycemia are can cause cognitive impairment. However, the underlying mechanism is not well understood. ${ }^{28}$ Despite the impact of poor glycemic control and impair academic performance, previous study showed the association between better control and the improvement of academic function. ${ }^{28}$ It can be an incentive to all professionals to provide the multi-disciplinary support (e.g., public education system, school, health care providers) to children with DM, with close observation for signs of hypoglycemia, and rapid responses by parents or teachers trained to respond to children's hypoglycemic episodes. ${ }^{29}$ 


\section{Asthma}

Among childhood chronic illnesses, asthma is the most frequent cause of school absenteeism. More than half of children with asthma missed school days due to asthma exacerbation or other related respiratory symptoms. ${ }^{30}$ Previous studies showed that asthmatic symptom-related absenteeism was associated with poor school performance and with lower grade point in elementary school students but not in high school students. ${ }^{30}$ However, earlier studies on college students have demonstrated that students with asthma miss 2.8 days on average of class due to asthma during a semester. ${ }^{31}$ They have lower cumulative grade point averages than students without asthma. ${ }^{32}$ However, inhaled corticosteroid use was the most important predicting factors for better academic performance in children with asthma. ${ }^{30}$

\section{Cancer}

Childhood cancer survivors have increased psychosocial functioning which may be exacerbated by school absenteeism. ${ }^{33}$ School absenteeism has led to poor academic performance. School absence was mostly due to physical health problems. Beyond school absenteeism, meta-analyses illustrated long-term cognitive impairment occurring after cancer treatment with and without cranial radiation. ${ }^{34,35}$ General intelligence was most affected. Compared with healthy peers, the IQ scores of children with acute lymphoblastic leukemia were 6 to 8 points lower. Working memory and processing speed were also affected. ${ }^{36}$ Reading and spelling was within expectations, but mathematical achievement tended to remain inferior to reading and spelling scores. ${ }^{34-36}$

\section{Congenital heart diseases}

Children with congenital heart diseases showed deficits of intelligence, attention, executive function, and academic achievement. ${ }^{37}$ Approximately one-quarter of children with congenital heart diseases have other anomalies or identified genetic syndrome which related to cognitive impairment and school problems. ${ }^{38,39}$ In children with congenital heart diseases without underlying genetic syndromes, mean IQ scores fall within the normal range. ${ }^{39}$ Children with cyanotic heart diseases (e.g., Tetralogy of Fallot, transposition of the great arteries) has shown greater impairments comparing to non-cyanotic heart diseases. ${ }^{39}$ Heart/ung transplantation has increased risks for lower academic performance associated with cardiopulmonary bypass during surgery. ${ }^{40}$

\section{Human Immunodeficiency Virus infection}

Human Immunodeficiency Virus (HIV) infection itself does not likely to affect cognitive function. ${ }^{41}$ However, severe HIV disease significantly increases the risk for cognitive function impairment because HIV disease has progressed extensively, especially with CNS involvement. ${ }^{42}$ Resent studies show that children with perinatal HIV infection had poorer performances in visual recognition memory and verbal learning compared with uninfected children. ${ }^{43}$

\section{Assessment}

Health care professionals often use a specific diagnosis of chronic illnesses to label children who require special educational support. However, the information on the child's abilities and the functional impairment of the illnesses may be a more practical way to deal with chronic illness-related school problems so that appropriate educational plans can be developed. ${ }^{44}$ Health care professionals can play an important role in the assessments of the functional abilities of children with chronic illnesses by intentional history taking so that optimal goals for enhancing their development can be developed. $^{45}$

Beyond the routine non-structural assessment, the Children with Special Health Care Needs Screener and 
the Questionnaire for Identifying Children with Chronic Conditions-Revised have been empirically accepted structural tools that were used to assess school-age children with chronic illnesses. ${ }^{46}$ These questionnaires identify parental perceptions, differences in symptoms, and severity. ${ }^{47}$

\section{Management}

Children with difference chronic illnesses have unique specific needs. However, all children share in the need for education. ${ }^{48} \mathrm{~A}$ supporting system should be developed in order to minimize the academic problems of chronically-illed children chronically early recognition and interventions. ${ }^{49}$ Healthcare professional can delivery of educational services to children with chronic illnesses in a three major approaches, as discussed below:

\section{School-based intervention}

Regular attending school is related to a sense of normal functioning in children with chronic illness. ${ }^{50}$ To maximize attendance and enhance academic performance, it is required coordinated school interventions. ${ }^{51}$ Teacher should design individual programs that integrate their health, psychological, and educational needs for children with chronic illness. ${ }^{14}$ Teacher and healthcare professionals should establish open discussions in both the medical and school settings. Training for teachers regarding the care of children who are chronically ill is required because teachers may feel less confident because of a lack of information about the child's medical problems. ${ }^{28,52}$

Intentional planning should be developed to resolve the current impromptu tendencies of teacher. Rynard et al. $^{53}$ recommended the school support programs for children with chronic illnesses. They described keys for effective school interventions as the followings; (1) helping children deal with absenteeism by providing home school or tutoring programs; (2) providing psychosocial support for children and their parents; (3) encouraging children to cope with medical fears; (4) assisting children and their parents to deal with the side effects of treatment; (5) developing emergency medical plans or disease-specific intervention for the classroom; (6) collaborating among parents, teachers, and the health care professionals; (7) collaborating in the development of educational plans and care plan to improve adherence to treatment, self-care, or school behaviors; (8) providing assessment and intervention to improve academic performance; and, (9) facilitating their coping with emotional and behavioral problems.

\section{Home-based intervention}

For some children with chronic illnesses, being discharged from a hospital does not mean being ready to attend school. Several chronic illnesses require home isolation. ${ }^{14}$ Home-based intervention can be provided either by the children's school teachers, or by a hospital teacher. ${ }^{14}$

The American Academy of Pediatrics, Committee on Children with School Health ${ }^{54,55}$ recommends 4 important features for home-based intervention: (1) teaching in a home-based program mirrors the content in the classroom; (2) monitoring the child's condition before returning to their school; (3) supervising parents during all home-based activities; and, (4) considering the health status of the children during the hours of home-based intervention.

Most home-based intervention is generally limited to 1 hour per day, and may not go into effect until an absence has exceeded 15 days. ${ }^{6}$ The limited intervention time provided through home-based intervention is clearly problematic. Although home-based intervention is not the ideal method for education, with good planning homebased intervention can be an effective narrow-gap way of uninterrupted schooling and it can provide to the normality of the lives of children. ${ }^{56}$ 


\section{Hospital schooling}

Education can be provided in a medical setting by hospital teachers in cases of long-term illness. Hospital schooling is usually run by the hospitals or the local public school system and are based on the same curriculum and method of evaluation. ${ }^{57}$ Hospital teachers have to ensure continuity of education and communicate with the children's own school. The limitation of this approach is that hospital teachers must provide instruction for many grade levels. Moreover, enrollment of hospital schools is very low when compared to traditional one. Despite the limitations, there have been a number of hospital school programs in many counties that show some benefits on closing the educational gaps of children with chronic illnesses. ${ }^{55}$

\section{Discussion}

Previous research shows that educational disabilities (i.e. dyslexia, dyscalculia, intellectual disabilities) received significant educational support and had better academic performance when compared to children with chronic health conditions, but without a clear educational disability. ${ }^{5}$ This review showed the association among chronic illnesses and child's academic performance. As expected, children with chronic illnesses were at an increased risk of academic difficulty in both general performance and specific domains of education. The association between chronic illnesses and academic performance is not disease-specific. ${ }^{58,59}$ Although there are some differences across illnesses, most research in this review show a commonality in terms of the educational, psychological, and social impacts. A non-categorical impact of chronic illnesses will inform the development of evaluation and management system applied to children with chronic illness, broadly, that could be more relevant to a wider range of children and their families than a disease-specific approach.
Early identification and interventions in children with a chronic illness are associated with better academic outcomes. Coordination between healthcare and educational services includes informal and/or structural screening to identify learning problems in children with chronic health conditions, which may prevent later behavior and psychiatric disorders and further improve the child's opportunities for academic success.

Although school reentry and school-based interventions seem to be the best management strategies for these children, alternative modes of educational services (homebound instruction and hospital schooling) are also important components for providing education to children who would otherwise not have adequate access to a general school setting.

\section{Conclusion}

Our review has potential implications for educational identification and intervention efforts for children with chronic illness. Healthcare professionals should change the focus from the diagnosis-based inclusion model for intervention for children with chronic illness. ${ }^{60}$ Inclusion for providing intervention should be based on the children's functioning rather than specific diagnosis because the impact of chronic illness is not disease-specific, and is pervasive across educational domains. As such, multidisciplinary team approach is critical in managing to the educational needs of children with chronic illness. ${ }^{61}$

\section{References}

1. Cox ER, Halloran DR, Homan SM, Welliver S, Mager DE. Trends in the prevalence of chronic medication use in children: 2002-2005. Pediatrics 2008;122:1053-61.

2. van der Lee JH, Mokkink LB, Grootenhuis MA, Heymans HS, Offringa M. Definitions and measurement of chronic health conditions in childhood: a systematic review. JAMA 2007;297:2741-51. 
3. Van Cleave J, Gortmaker SL, Perrin JM. Dynamics of obesity and chronic health conditions among children and youth. JAMA 2010;303;623-30.

4. Mokkink LB, van der Lee $\mathrm{JH}$, Grootenhuis MA, Offringa $M$, van Praag BMS, Heymans HSA. Omvang en gevolgen van chronische aandoeningen bij kinderen. Tijdschr Kindergeneeskd 2007;75:154-8.

5. Martinez YJ, Ercikan K. Chronic illnesses in Canadian children: what is the effect of illness on academic achievement, and anxiety and emotional disorders?. Child Care Health Dev 2009;35:391-401.

6. Martinez W, Carter JS, Legato LJ. Social competence in children with chronic illness: a meta-analytic review. J Pediatr Psychol 2011;36:878-90.

7. Sentenac M, Arnaud C, Gavin A, Molcho M, Gabhainn SN, Godeau E. Peer victimization among school-aged children with chronic conditions. Epidemiol Rev 2012;34:120-8.

8. Shaw SR, McCabe PC. Hospital-to-school transition for children with chronic illness: meeting the new challenges of an evolving health care system. Psychol Schs 2008;45:74-8.

9. Hilliard ME, McQuaid EL, Nabors L, Hood KK. Resilience in youth and families living with pediatric health and developmental conditions: introduction to the special issue on resilience. J Pediatr Psychol 2015;40:835-9

10. Pao M, Ludi E. Psychosomatic symptoms in children with chronic medical illness; understanding pediatric psychopharmacology in the context of medical illness. Psychiatr Times 2011;33:1-5.

11. Cobham VE, Hickling A, Kimball H, Thomas HJ, Scott JG, Middeldorp CM. Systematic review: anxiety in children and adolescents with chronic medical conditions. J Am Acad Child Adolesc Psychiatry 2019. doi: 10.1016/.jaac.2019.10.010.

12. Green $\mathrm{AE}$, Ferrand J, Aarons GA. Functioning among youth with comorbid mood disorder and chronic physical illness in public sector care. J Dev Behav Pediatr 2016;37:637-46.

13. Crump C, Rivera D, London R, Landau M, Erlendson B, Rodriguez E. Chronic health conditions and school performance among children and youth. Ann Epidemiol 2013;23: $179-84$.

14. Thies KM. Identifying the educational implications of chronic illness in school children. J Sch Health 1999;69:392-7.

15. Emerson ND, Distelberg B, Morrell HE, Williams-Reade J, Tapanes D, Montgomery S. Quality of life and school absen- teeism in children with chronic illness. J Sch Nurs 2016;32: 258-66.

16. Shaw SR, Glaser SE, Stern M, Sferdenschi C, McCabe PC. Responding to student's chronic illnesses. Principal Leadership 2010;26:12-6.

17. Compas BE, Jaser SS, Dunn MJ, Rodriguez EM. Coping with chronic illness in childhood and adolescence. Annu Rev Clin Psychol 2012;8:455-80.

18. Wo SW, Ong LC, Low WY, Lai PSM. The impact of epilepsy on academic achievement in children with normal intelligence and without major comorbidities: s systematic review. Epilepsy Res 2017;136:35-45.

19. Reilly C, Neville BG. Academic achievement in children with epilepsy: a review. Epilepsy Res 2011;97:112-23.

20. Berg AT, Langfitt JT, Testa FM, Levy SR, DiMario F, Westerveld $\mathrm{M}$, et al. Global cognitive function in children with epilepsy: a community based study. Epilepsia 2008;49:608-14.

21. Ellenberg JH, Hirtz DG, Nelson KB. Age of onset of seizures in young children. Ann Neurol 1984;15:127-34.

22. Murphy CC, Trevathan E, Yeargin-Allsopp M. Prevalence of epilepsy and epileptic seizures in 10-year-old children: results from the metropolitan Atlanta developmental disabilities study. Epilepsia 1995;36:866-72.

23. Sillanpää $M$, Jalava $M$, Kaleva $O$, Shinnar S. Long-term prognosis of seizures with onset in childhood. N Engl J Med 1998;338:1715-22.

24. Oostrom KJ, Smeets-Schouten A, Kruitwagen CL, Peters AC, Jennekens-Schinkel A. Not only a matter of epilepsy: early problems of cognition and behavior in children with 'epilepsy only' - a prospective controlled study starting at diagnosis. Pediatrics 2003;112:1338-44.

25. Barza L. Cognition and achievement in children with seizure disorders. Eur Sci J 2014;10:107-20.

26. García-Peñas JJ. Interictal epileptiform discharges and cognitive impairment in children. Rev Neurol 2011;52:S43-52.

27. Kim HG. Cognitive dysfunctions in individuals with diabetes mellitus. Yeungnam Univ J Med 2019;36:183-91.

28. Kodl CT, Seaquist ER. Cognitive dysfunction and diabetes mellitus. Endocr Rev 2008;29:494-511.

29. Holmes CS, O’Brien B, Greer T. Cognitive functioning and academic achievement in children with insulin-dependent diabetes mellitus (IDDM). School Psychol Quart 1995;10:329_ 44. 
30. Tsakiris A, lordanidou M, Paraskakis E, Tsalkidis A, Rigas A, Zimeras S, et al. The presence of asthma, the use of inhaled steroids, and parental education level affect school performance in children. Biomed Res Int 2013. doi: 10.1155/ $2013 / 762805$.

31. Jolicoeur LM, Boyer JG, Reeder CE, Turner J. Influence of asthma or allergies on the utilization of health care resources and quality of life in college students. J Asthma 1994;31:25167.

32. Carpentier MY, Mullins LL, Van Pelt JC. Psychological, academic, and work functioning in college students with childhood-onset asthma. J Asthma 2007;44:119-24.

33. French AE, Tsangaris E, Barrera M, Guger S, Brown R, Urbach S, et al. School attendance in childhood cancer survivors and their siblings. J Pediatr 2013;162:160-5.

34. Campbell LK, Scaduto M, Sharp W, Dufton L, Van Slyke D, Whitlock JA, et al. A meta-analysis of the neurocognitive sequelae of treatment for childhood acute lymphocytic leukemia. Pediatr Blood Cancer 2007;49:65-73.

35. Iyer NS, Balsamo LM, Bracken MB, Kadan-Lottick NS. Chemotherapy-only treatment effects on long-term neurocognitive functioning in childhood ALL survivors: a review and meta-analysis. Blood 2015;126:346-53.

36. Harshman LA, Barron S, Button AM, Smith BJ, Link BK, Lynch CF, et al. Population-based exploration of academic achievement outcomes in pediatric acute lymphoblastic leukemia survivors. J Pediatr Psychol 2012;37:458-66.

37. Todaro JF, Fennell EB, Sears SF, Rodrigue JR, Roche AK. Review: cognitive and psychological outcomes in pediatric heart transplantation. J Pediatr Psychol 2000;25: 567-76.

38. Pierpont ME, Basson CT, Benson DW Jr, Gelb BD, Giglia TM, Goldmuntz E, et al. Genetic basis for congenital heart defects: current knowledge: a scientific statement from the American Heart Association Congenital Cardiac Defects Committee, Council on Cardiovascular Disease in the Young: endorsed by the American Academy of Pediatrics. Circulation 2007;115:3015-38.

39. Wright M, Nolan T. Impact of cyanotic heart disease on school performance. Arch Dis Child 1994;71:64-70.

40. Wray J, Long T, Radley-Smith R, Yacoub M. Returning to school after heart or heart-lung transplantation: how well do children adjust?. Transplantation 2001;72:100-6.
41. Blanchette N, Smith ML, King S, Fernandes-Penney A, Read S. Cognitive development in school-age children with vertically transmitted HIV infection. Dev Neuropsychol 2002;21:22341.

42. Smith R, Chernoff M, Williams PL, Malee KM, Sirois PA, Kammerer B, et al. Impact of HIV severity on cognitive and adaptive functioning during childhood and adolescence. Pediatr Infect Dis J 2012;31:592-8.

43. Nichols SL, Chernoff MC, Malee K, Sirois PA, Williams PL, Figueroa $V$, et al. Learning and memory in children and adolescents with perinatal HIV infection and perinatal HIV exposure. Pediatr Infect Dis J 2016;35:649-54.

44. Stille CJ, Antonelli RC. Coordination of care for children with special health care needs. Curr Opin Pediatr 2004;16: 700-5.

45. Palfrey JS, Sofis LA, Davidson EJ, Liu J, Freeman L, Ganz ML. The Pediatric Alliance for Coordinated Care: evaluation of a medical home model. Pediatrics 2004;113:1507-16.

46. Bethell CD, Read D, Neff J, Blumberg SJ, Stein RE, Sharp V, et al. Comparison of the children with special health care needs screener to the questionnaire for identifying children with chronic conditions--revised. Ambul Pediatr 2002;2:49-57.

47. Rolnick SJ, Flores SK, Paulsen KJ, Thorson S. Identification of children with special health care needs within a managed care setting. Arch Pediatr Adolesc Med 2003;157:273-8.

48. Shiu S. Issues in the education of students with chronic illness. Int J Disabil Dev Edu 2001;48:269-81.

49. Ris MD, Beebe DW. Neurodevelopmental outcomes of children with low-grade gliomas. Dev Disabil Res Rev 2008;14:196-202.

50. Capurso M. Children with chronic illness in school. Difficoltà di apprendimento 2006;12:51-70.

51. Sexson S, Madan-Swain A. The chronically ill child in the school. Sch Psychol Q 1995;10:359-68.

52. Worchel-Prevatt FF, Heffer RW, Prevatt BC, Miner J, YoungSaleme T, Horgan D, et al. A school reentry program for chronically ill children. J Sch Psychol 1998;36:261-79.

53. Rynard DW, Chambers A, Klinck AM, Gray JD. School support programs for chronically ill children: evaluating adjustment of children with cancer at school. J Child Health Care 1998;27:31-46.

54. American Academy of Pediatrics, Committee on Children 
with Disabilities. Provision of educationally related services for children and adolescents with chronic diseases and disabling conditions. Pediatrics 2000;105:448-51.

55. American Academy of Pediatrics, Committee on Children with Disabilities. Provision of educationally related services for children and adolescents with chronic diseases and disabling conditions. Pediatrics 2007;119:1218-23.

56. Shaw SR, Clyde MAJ, Sarrasin M. Homebound instruction for students with chronic illness: reducing risk outside of the box. Health Psychology Report 2014;2:1-9.

57. Covic AN, Kanemoto E, Bastos AC. Effectiveness of a hospital school mathematics literacy program. Stud Health Technol Inform 2012;172:168-73.

58. Goldfeld S, O'Connor M, Sayers M, Moore T, Oberklaid F.
Prevalence and correlates of special health care needs in a population cohort of Australian children at school entry. J Dev Behav Pediatr 2012;33:319-27.

59. Quach J, Barnett T. Impact of chronic illness timing and persistence at school entry on child and parent outcomes: Australian Longitudinal Study. Acad Pediatr 2015;15:89-95.

60. O'Connor M, Howell-Meurs S, Kvalsvig A, Goldfeld S. Understanding the impact of special health care needs on early school functioning: a conceptual model. Child Care Health Dev 2015;41:15-22.

61. Ng CY, Thomas-Uribe M, Yang YA, Chu MC, Liu SD, Pulendran UP, et al. Theory-based health behavior interventions for pediatric chronic disease management: a systematic review. JAMA Pediatr 2018;172:1177-86. 